\title{
Rediscovery of a petrel and new faunal records on Gau Island
}

\author{
Dick Watling
}

MacGillivray's or the Fiji petrel was known only from a single specimen collected in $\mathbf{1 8 5 5}$ on Gau Island. In 1984, after months of searching, a single adult flew into Dick Watling's spotlight and collided with his head. It was examined, photographed and released. Nothing more is yet known about its status or its breeding site, although the latter is suspected to be in the cloud forests of highland Gau. In the course of his visits, the author also made other discoveries about the Island's poorly studied fauna.

Gau (pronounced 'ngau' with a soft 'ng') is Fiji's fifth largest island, with an area of $140 \mathrm{sq} \mathrm{km}$. The land is rugged, and 55 per cent supports dense rain forest, comprising the high land in the north, which is dominated by the summits Delcaco ( 715 $\mathrm{m})$ and Delacoboni $(705 \mathrm{~m})$, and the main ridge running south. The rolling country of the eastern coast and the Island's extremities is covered with grass or reed, but is increasingly being planted with Pinus caribaea.

Although Gau Island lies less than $80 \mathrm{~km}$ from Suva, Fiji's capital on the island of Viti Levu, its fauna has received only the most superficial study. HMS Herald, a Royal Navy survey ship, mapped the island during two visits in 1854 and 1855. John MacGillivray was the naturalist on board on the first visit, and a few of his observations survive in his journal. In April 1855, while the Herald was refurbishing in Sydney, Australia, MacGillivray was dismissed and the ship returned to Gau with the Medical Officer, Dr F. M. Rayner, acting as naturalist. Rayner's bird-collection from Gau included a new species of petrel, later described by G. R. Gray of the British Museum as Thalassidroma (Bulweria) macgilliurayi: It was Gau Island: a rediscovered petrel clear that MacGillivray had nothing to do with the collection of the specimen, but whether Gray knew that MacGillivray had left the Herald under a cloud and was nonetheless rewarding him for past services, is not known. It is, in any case, more appropriate to refer to the bird as the Fiji petrel rather than MacGillivray's petrel. The petrel, now named Pseudobulweria macgillivrayi (Imber, 1985), was not seen again, despite a visit, in February 1925, by the Whitney South Sea

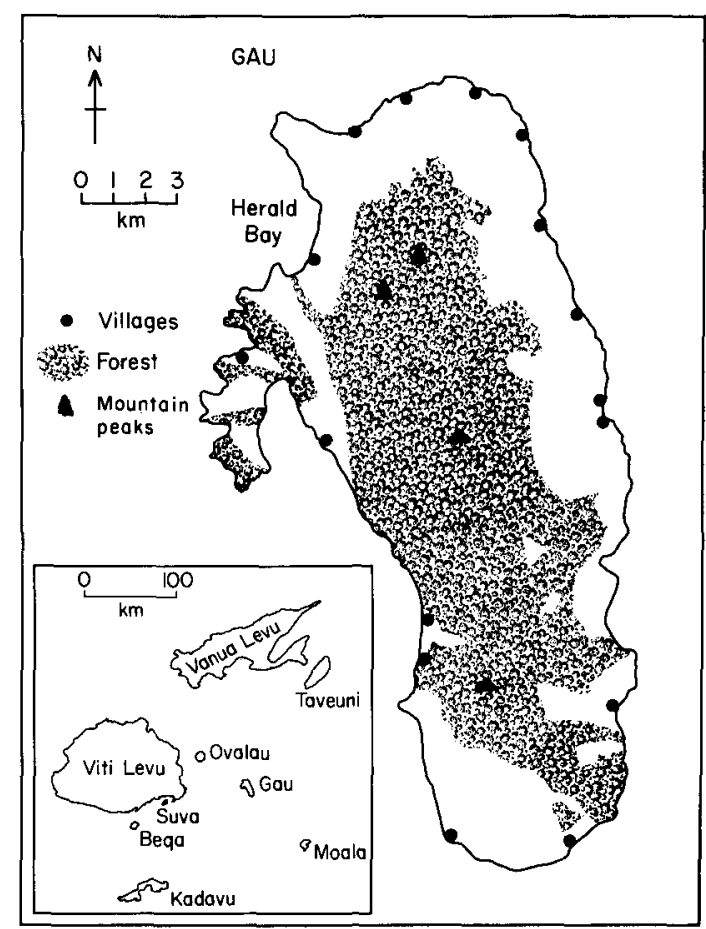

Gau, and its location within the Fiji Islands. 
Expedition of the American Museum of Natural History, which collected a small number of birds.

In 1983 I initiated a search for this 'missing petrel' (Bourne, 1965) and also took the opportunity to make the first extensive observations of Gau's fauna. The search spanned 16 months, May 1983-August 1984, with visits of 1-3 weeks every two months (Watling and Lewanavanua, 1985). Villagers were questioned and a reward was offered for information about the Fiji petrel, but none was forthcoming. On the first visit we found what we suspected were nesting burrows of collared petrels Pterodroma brevipes, and our suspicions were confirmed when villagers captured a young bird about to leave a nesting burrow in August 1983. This is the first breeding record for Gau of this species, which is known to breed only on certain islands in Fiji, Vanuatu and probably Samoa.

The search for the Fiji petrel continued in potential nesting habitat in the highlands. There were signs of feral cats, and remains of collared petrels were identified in scats and killings, but none of the Fiji petrel. In February 1984 we heard and recorded our first collared petrel calls, and on subsequent visits used these recordings, with our spotlights, in an attempt to attract petrels to us. In April, on four nights of the new moon with very poor weather, we succeeded in attracting 165 collared petrels to a site near the summit.

On the night of 30 April our search was at last rewarded. A single adult Fiji petrel flew into our light. We examined, measured and weighed it. Next day, the petrel was photographed, shown to the villagers, and then released by the Paramount Chief of Gau. This was our first and last record of the petrel.

Although we now know that the species survives, we know nothing of its population size or where it breeds. Gau appears to have sufficient suitable habitat to support a large population, but it is undoubtedly small, otherwise this distinctive petrel would have been seen at sea. The difficulty in finding its nesting burrows will be compounded by the presence of large numbers of collared petrel burrows.

Since the introduced mongoose Herpestes auropunctatus has, as far as is known, eliminated 32 all nesting colonies of the collared petrel on Fiji's largest islands, Viti Levu and Vanua Levu, Gau must now be considered as one of this species's most important breeding sites. It seems likely that the replacement of the grass and reed, where petrels cannot breed, by pines will be beneficial as petrels should be able to burrow under the trees.

Petrels are not persecuted by Gau villagers, their only predators being introduced rats, Rattus exulans and $R$. norvegicus, and feral cats. The collared petrel appears able to nest successfully, perhaps because its synchronized nesting during the first half of the year swamps cat predation. If, as is suggested by the fact that the Herald specimen, a first-flight young, was collected in October, the Fiji petrel has a more extended and later breeding season, that species may suffer disproportionately from predation. The fact that feral pigs are absent from Gau is certainly beneficial for nesting petrels.

Gau is Fiji's largest island without either feral pigs or jungle fowl, and provides a unique opportunity for investigating the possible effects that these aboriginal introductions may have had on Fiji's terrestrial fauna and flora. Considering Gau's large size, proximity to other major islands and extensive rain forest, its avifauna has a low diversity. While forest specialists are notoriously poor dispersers in insular avifaunas, it is perhaps surprising that not one of half-a-dozen possible species have reached Gau from Viti Levu, only 59 $\mathrm{km}$ away. Gau does, however, support a thriving population of the nominate race of the redbreasted musk parrot Prosopeia t. tabuensis. Whether Gau is the origin of the introduced Tongan population of this race, or whether they are both hybrid populations of the other four races of this Fijian parrot, is not yet known. The Tongan population still survives on the island of 'Eua, which I visited in February 1983, but its future in the face of unabated habitat destruction is far bleaker than that of the Gau population. Another forest bird, the distinctive, all-black race of the island thrush, Turdus poliocephalus hades, which is endemic to Gau, is common, but the female remains undescribed. We found Layard's white-eye Zosterops explorator to be common, and this represents an important range extension for this Fijian endemic.

Oryx Vol 20 No 1, January 1986 

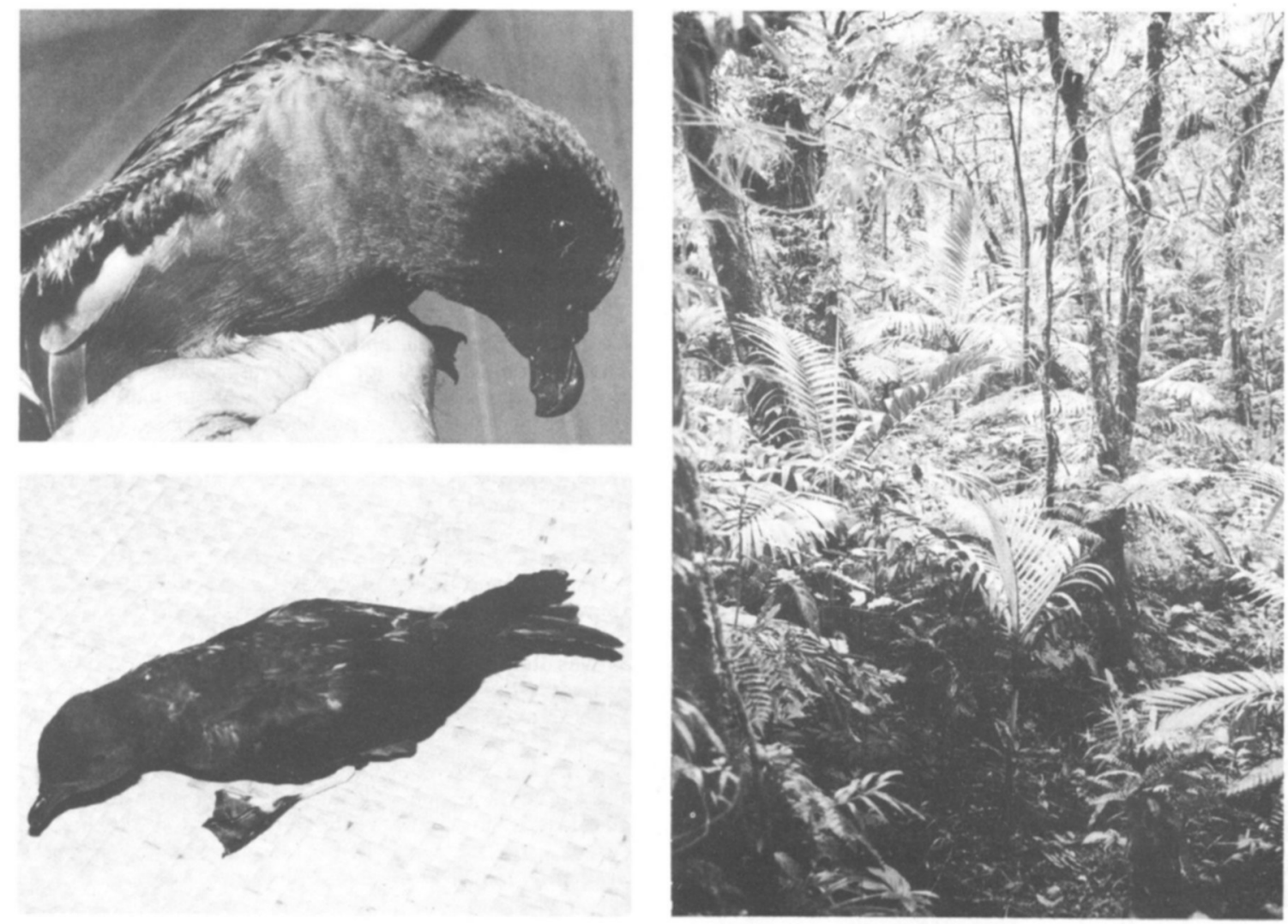

Top left: The Fiji petrel, showing its robust bill (Dick Watling). Middle left: The feet of the Fiji petrel are heavy and bicoloured (Dick Watling).

Top right: Potential nesting habitat; thick ridge forest with an abundance of Physokentia rosacea palms (Dick Watling). Bottom: View of the interior of Gau, showing rugged hills clad with mature rain forest (Dick Watling).

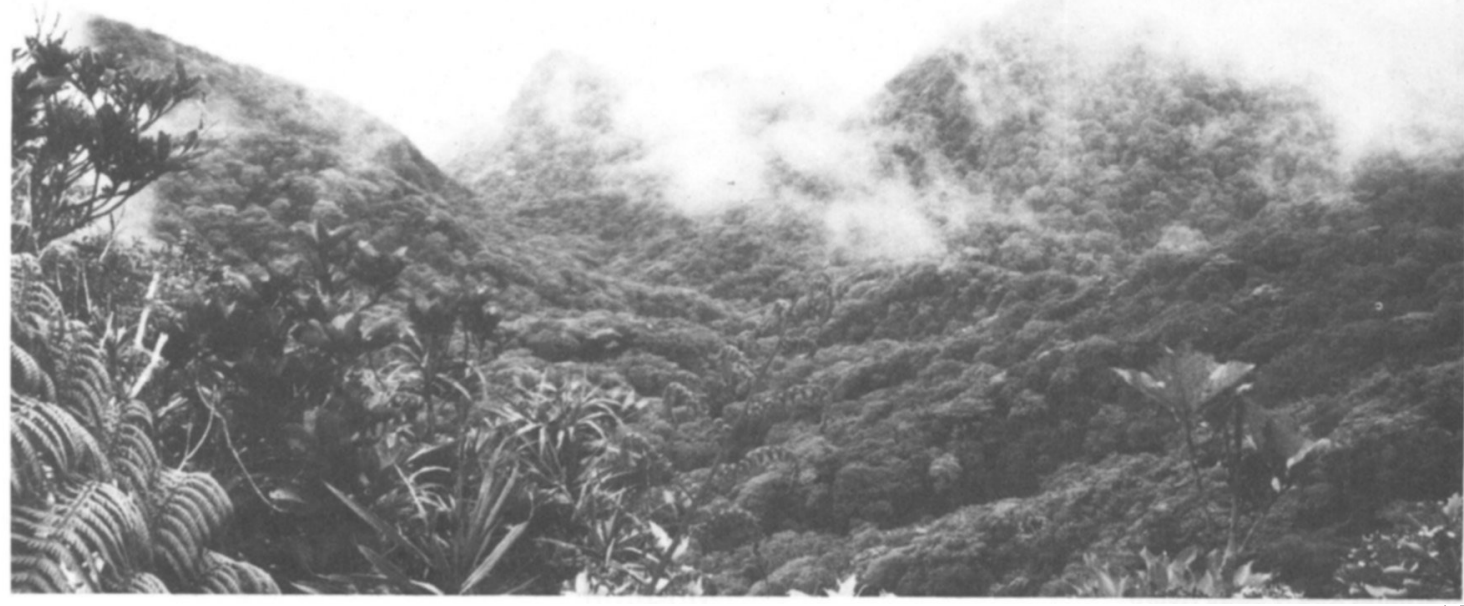


It is more surprising that three open-country birds, which disperse more easily than forest species, the wattled honeyeater Foulehaio carunculata, Polynesian triller Lalage maculosa and the slaty flycatcher Mayromis lessoni are missing from Gau. These three birds have a wide habitat tolerance, are usually common wherever they occur, and their distribution encompasses the entire Fijian archipelago, including many of the smallest islands (Watling, in prep.). The absence of so many small passerines on Gau might be beneficial for future conservation. If any of Fiji's insular endemics become endangered through habitat destruction, translocation to Gau could be considered, but at present no species gives cause for concern.

The reptile fauna of Gau is rich, despite the presence of feral cats. We found the banded iguana Brachylophus fasciatus, and an undescribed species of Emoid skink, both of which are probably common on the Island, as well as Fiji's largest gecko Gehyra vorax. A major finding was the discovery of a population of the endemic Fiji ground frog Platymantis vitianus. The ground frog still manages to survive on the mongooseinfested islands of Viti Levu, Vanua Levu and Beqa, but these populations must be considered doomed in the long-term. Only the populations on Taveuni and Ovalau, and now on Gau, can be considered secure from this predator. However, the Gau population alone faces no competition from the cane toad Bufo marinus, which has been introduced and is abundant on Taveuni and Ovalau, but not on Gau.

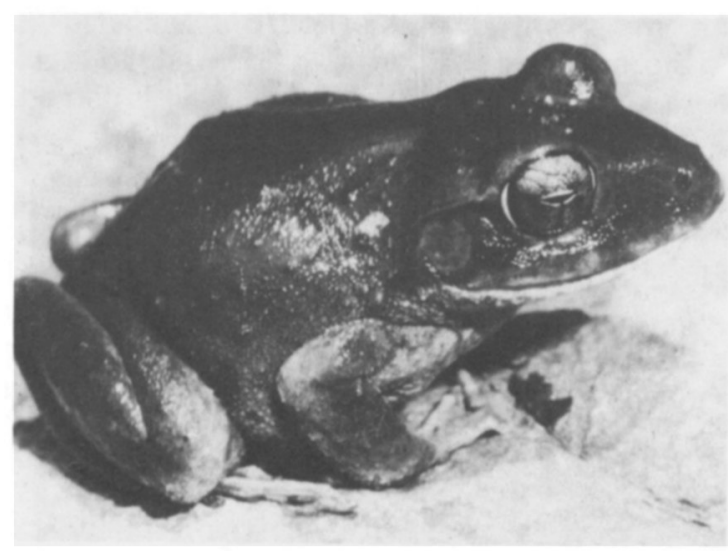

Fiji ground frog (Paddy Ryan).
The most important conservation priority on Gau at the moment is to educate the islanders against a chance introduction of the mongoose. If it reaches Gau, both species of petrel, the four rails, many of the reptiles and the ground frog may all become extinct.

\section{Acknowledgments}

The search was sponsored by the Central Manufacturing Company, Suva, Fiji, and was assisted by a grant from the International Council for Bird Preservation, UK. Fiji Air assisted with air travel to Gau-without their generous support the search could not have taken place. The help of Ratu Marika Uluidawa Lewanavanua, the Paramount Chief of Gau, was crucial to the success of the search and, in addition, the hospitality of his wife, Adi Ta, and household was overwhelming. Many villagers helped during the fieldwork, none more than Kinijioji Vererusa; we are most grateful to them all. Mark Pizey and Edward Dugdale assisted the fieldwork with characteristic humour, albeit sceptical! In Suva, Tony Sansom's help and hospitality were relied on too frequently, as was that of Kelera Wea. Dr W. R. P. Bourne has long suspected the presence of this 'missing' petrel on Gau and encouraged a search for it. His help, and that of Dr Mike Imber, is especially and gratefully acknowledged. Mr David Crockett, Lt Cmdr A.C. David, Mr Ian Galbraith, Dr Rod Hay and Captain J. Jenkins all corresponded at length, answering many questions and providing very useful suggestions. $\mathrm{Mr}$ Fergus Clunie, Director of Fiji Museum, assisted in several ways and made freely available his store of local knowledge. I am very grateful to Harry Harrisson, without whose yacht 'FYXE' we could not have made a sea search. Finally, the search benefited in inumerable ways from the help and support of Murray and Shirley Charters.

\section{References}

Bourne, W.R.P. 1965. The Missing Petrels, Bull. B.O.C. 85, 97-105.

Imber, M.J. 1985. Origins, phylogeny and taxonomy of gadfly petrels Pterodroma spp. Ibis, 127, 197-229.

Watling, D. (in prep.) On the distribution of the Wattled Honeyeater Foulehaio carunculata and the Polynesian Triller Lalage maculosa in the Fijian islands.

Watling, D. and Lewanavanua, RatuF. 1985. A note to record the continuing survival of the Fiji (MacGillivray's) Petrel Pseudobulweria macgilliurayi. Ibis, 127, 230-233.

Dick Watling, Box 2041, Government Buildings, Suva, Fiji.

\section{Postscript}

A Fiji petrel, which had probably just left the nest, flew into village lights on the night of 3 July 1985. It was weak, possibly injured, all attempts to liberate it failed, and unfortunately, after a week it died. The specimen is preserved at the Fiji Museum.

Oryx Vol 20 No 1, January 1986 